\title{
Os fluxos escolares na educação profissional técnica de nível médio em uma escola técnica e suas relações com processos de ensino, de aprendizagem e de avaliação
}

\section{The school flows in the technical trofessional secondary level education at tecnhical school and their relations with teaching, learning and assessment processes}

\section{Flujos escolares en la educación secundaria técnica en una escuela técnica y sus relaciones con los procesos de enseñanza, aprendizaje y evaluación}

\author{
Ribeiro, Caroline Lourenço de Almeida ${ }^{1}$ (Santa Rita do Sapucaí, MG, Brasil) \\ ORCID ID: https://orcid.org/0000-0003-1411-970X \\ Fritsch, Rosangela ${ }^{2}$ (São Leopoldo, RS, Brasil) \\ ORCID ID: https://orcid.org/0000-0002-0630-3649
}

\begin{abstract}
Resumo
Neste artigo são analisados efeitos dos processos de ensino, de aprendizagem e avaliação nos fluxos escolares dos estudantes do ensino médio concomitante na Escola Técnica de Eletrônica Francisco Moreira da Costa (ETE FMC). A pesquisa evidencia relevância social na medida que oferece um diagnóstico que possibilita promover melhorias no projeto pedagógico. Ela tem como relevância acadêmica, o propósito de preencher uma lacuna na produção acadêmica pelo fato de investigar fatores intervenientes nos fluxos escolares correlatos às práticas pedagógicas, que possui baixa incidência de estudos com esse foco. Metodologicamente, adotou-se abordagem qualitativa, exploratória e estudo de caso. Foram realizadas entrevistas semiestruturadas com estudantes do $1^{\circ}$ ano do ensino médio concomitante reprovados e transferidos em 2018. Entre os resultados verificamos uma incidência maior do insucesso escolar, nos estudantes do $1^{\circ}$ ano do ensino médio concomitante e dos estudantes beneficiários de bolsa CEBAS em relação aos demais. Quanto aos fatores intervenientes que se refletem nos fluxos escolares, destacamos processos de ensino, de aprendizagem e de avaliação sustentados no paradigma instrucionista e fragilidades socioeconômicas, culturais e familiares se ressaltaram. Concluímos que os processos analisados têm consequências positivas e negativas sobre os fluxos escolares. Diferentes paradigmas pedagógicos coexistem na escola, no entanto, o paradigma da instrução merece questionamento. Como limites deste estudo, registramos a necessidade de envolvimento de mais atores do processo educativo, como os docentes.
\end{abstract}

Palavras-chave: Ensino. Aprendizagem. Fluxos escolares. Ensino médio.

\begin{abstract}
In this article, the effects of teaching, learning and assessment processes on the school flows of high school concomitant students are analyzed at Francisco Moreira da Costa Electronics Technical School (ETE FMC). The research shows social relevance as it offers a diagnosis that makes it possible to promote improvements in the pedagogical project. It has as academic relevance, the purpose of filling a gap in academic production by investigating intervening factors in school flows linked to pedagogical practices, which has a low incidence of studies on this focus. Methodologically, It was used a qualitative, exploratory and case study. Semi-structured interviews were carried out with 1st year high school concomitant students who had failed or were transferred in 2018. Among the results, we verified a higher incidence of school failure in concomitant students in the 1st year of high school and of students who received a scholarship (CEBAS) in relation to the other ones. Relating to the intervening factors that are reflected in school flows, we highlight teaching, learning and assessment processes based on socioeconomic, cultural and family weaknesses and instructional paradigm. We concluded that the analyzed processes have positive and negative consequences on the school flows. Different pedagogical paradigms coexist at school; however, the instruction paradigm deserves questioning. As limits of this study, we registered the need to involve more elements of the educational process, such as teachers.
\end{abstract}

Keywords: Teaching. Learning. School flows. High school.

\footnotetext{
${ }^{1}$ Professora e coordenadora do Ensino Médio na Escola Técnica de Eletrônica Francisco Moreira da Costa (ETE FMC). carolinelar.2ls@gmail.com

${ }^{2}$ professora titular no Programa de Pós-Graduação em Educação (Acadêmico), na Graduação e Especializações da Unisinos. rosangelaf@unisinos.br
} 


\section{Resumen}

En esto artículo se analizan los efectos de los procesos de enseñanza, aprendizaje y evaluación en los flujos escolares de los estudiantes de secundaria de la Escola Técnica de Eletrônica Francisco Moreira da Costa (ETE FMC). La investigación muestra relevancia social al ofrecer un diagnóstico que permite promover mejoras en el proyecto pedagógico. Además, tiene el propósito de llenar un vacío en la producción académica al investigar factores intervinientes en los flujos escolares correlacionados con las prácticas pedagógicas, lo que tiene una baja incidencia en los estudios con este enfoque. Se adoptó una metodología cualitativa, exploratoria y de estudio de casos, con la realización de entrevistas semiestructuradas con estudiantes de primer año de bachillerato concomitante que habían reprobado o transferido en el año 2018. Entre los resultados, se encontró una mayor incidencia de fracaso escolar en estudiantes de primer año de bachillerato concomitante y de los becarios CEBAS en comparación con los demás. En cuanto a los factores intervinientes que se reflejan en los flujos escolares, se destacan los procesos de enseñanza, aprendizaje y evaluación sostenidos en el paradigma instruccionista y aún las debilidades socioeconómicas, culturales y familiares. Finalmente se concluye que los procesos analizados tienen consecuencias positivas y negativas sobre los flujos escolares. En la escuela conviven diferentes paradigmas pedagógicos. Sin embargo, el paradigma de la instrucción merece ser cuestionado. Como límites de este estudio, se registra la necesidad de enredar a más actores del proceso educativo, como los profesores.

Palavras-Clave: Aprendizaje. Educación Secundaria. Enseñanza. Flujos escolares.

\section{Introdução}

O tema central deste artigo são os fluxos escolares e suas relações com processos de ensino, de aprendizagem e de avaliação. Serão apresentados resultados de um estudo de caso, no qual analisamos efeitos destes processos sobre os fluxos escolares dos estudantes da Educação Profissional de Nível Médio, no caso, do ensino médio concomitante, da Escola Técnica de Eletrônica Francisco Moreira da Costa (ETE FMC).

$\mathrm{Na}$ literatura, muitos estudos abordam a temática dos fluxos escolares, tratando da reprovação, da evasão escolar e da permanência e, ainda, da desistência no ensino médio (Faria e Moura, 2015; Ferraz, 2015; Meira, 2015; Morais, 2017; Pontili, 2015; Yokota, 2015). No entanto, identificamos escassez de pesquisas que relacionem fluxos escolares com práticas pedagógicas. A pesquisa de Morais (2017) é a que mais se aproxima deste estudo ao investigar a relação entre fluxos escolares com o processo avaliativo. De modo geral, encontraram-se produções acadêmicas que se correlacionam com fluxos escolares, evasão, abandono e questões socioculturais separadamente, porém, nenhuma estabelece diálogo entre fluxos escolares e processos pedagógicos.

O Índice de Desenvolvimento da Educação Básica (IDEB) é um dos indicadores educacionais existentes que se compõe com fluxo escolar. Ele foi criado em 2007 e reúne, em um só indicador, os resultados de dois conceitos importantes para a qualidade da educação: o fluxo escolar e as médias de desempenho nas avaliações (INEP, 2021). Portanto, compõe-se com taxa de aprovação escolar do 
Censo Escolar e das médias de desempenho no Sistema de Avaliação da Educação Básica (Saeb).

$\mathrm{Na}$ educação básica, as taxas de rendimento retratam a situação do estudante ao término do ano letivo, as quais elencam três possibilidades: aprovação, reprovação ou abandono. Por outro lado, as taxas de transição ou fluxo, "avaliam a transição do estudante entre dois anos consecutivos, considerando os seguintes cenários: promoção, repetência, migração para EJA e evasão escolar" (INEP, 2019). As taxas de rendimento e de transição ou fluxo escolar podem ser mais bem visualizadas na figura 1 .

Figura 1 - Taxa de rendimento e transição dos alunos
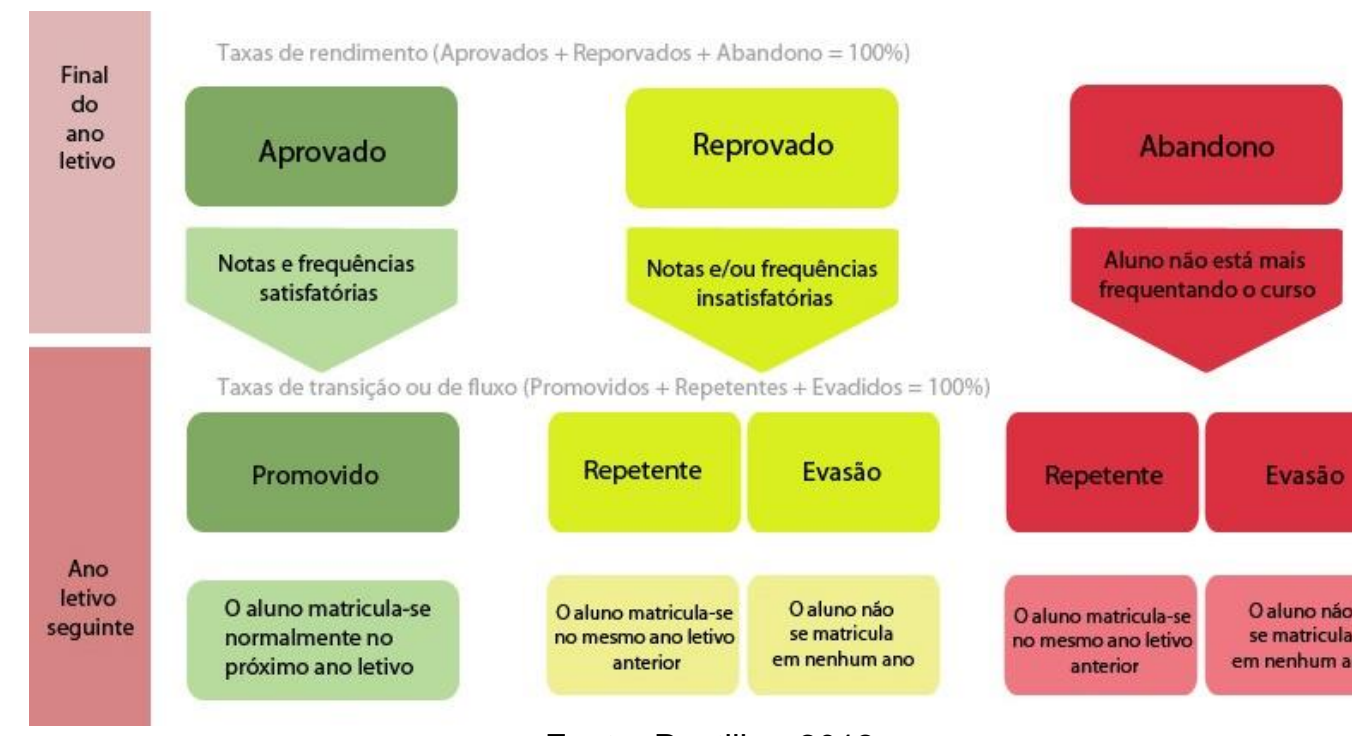

Fonte: Pontilho, 2012.

Segundo informações do portal de dados QEdu (2021), taxas de reprovação e abandono superiores a $5 \%$ indicam a necessidade de criação de estratégias para se conter o avanço da evasão escolar. Já as taxas superiores a 15\% apontam a necessidade de intervenção pedagógica, dado o elevado número de estudantes que ficariam fora da escola, havendo, ainda, aumento da distorção idadesérie.

Em 2018, a taxa de transição nas escolas privadas urbanas do Brasil, no ensino médio, foi de $3,7 \%$ de reprovação, $0,3 \%$ de abandono e $96 \%$ de aprovação. No mesmo ano, quando fragmentada por série, a taxa de rendimento tem porcentagem maior de reprovação e abandono na $1^{\text {a }}$ série, com $6,1 \%$ de estudantes reprovados e $0,4 \%$ em abandono. Os dados melhoram no decorrer do ensino médio, com aumento de aprovações entre os estudantes que permaneceram. Dessa forma, 
o $3^{\circ}$ ano apresenta o melhor resultado, com $98,5 \%$ de aprovação, como pode ser observado na figura 2.

Figura 2 - Taxa de transição por ano escolar em 2018

\begin{tabular}{|c|c|c|c|}
\hline Ensino Médio & Reprovação & Abandono & Aprovação \\
\hline $1^{\circ}$ ano EM & $\begin{array}{l}6,1 \% \\
19.823 \text { reprovaç̄es }\end{array}$ & $\begin{array}{l}0,4 \% \\
1.300 \text { abandonos }\end{array}$ & $\begin{array}{l}93,5 \% \\
303.833 \text { aprovaç̄es }\end{array}$ \\
\hline $2^{\circ}$ ano EM & $\begin{array}{l}3,2 \% \\
9.573 \text { reprovaç̆es }\end{array}$ & $\begin{array}{l}0,3 \% \\
898 \text { abandonos }\end{array}$ & $\begin{array}{l}96,5 \% \\
288.675 \text { aprovaçōes }\end{array}$ \\
\hline $3^{\circ}$ ano EM & $\begin{array}{l}1,3 \% \\
3.571 \text { reprovaç̃oes }\end{array}$ & $\begin{array}{l}0,2 \% \\
550 \text { abandonos }\end{array}$ & $\begin{array}{l}98,5 \% \\
270.559 \text { aprovaçốes }\end{array}$ \\
\hline
\end{tabular}

Fonte: INEP/Censo, 2018.

Em consonância, os dados institucionais da ETE FMC, em 2018, despertam algumas preocupações. Entre as três modalidades ofertadas pela escola — ensino médio concomitante ao técnico, ensino médio regular e técnico noturno -, os índices de reprovação, transferência e cancelamento se acentuam nas primeiras séries do ensino médio concomitante, com $24 \%$, do médio regular, com $33 \%$, e do $1^{\text {o }}$ módulo do técnico noturno, com $35 \%$.

Partimos da hipótese de que os processos de ensino, de aprendizagem e de avaliação podem promover efeitos positivos e negativos sobre os fluxos escolares, quando combinados com outras variáveis, como questões socioeconômicas dos estudantes, lacunas de aprendizagem, entre outros fatores.

Quanto à estrutura, este artigo é composto por sete seções. Nesta presente introdução, apresentamos o tema e objetivo, contextualizando e problematizando o fenômeno analisado. Na segunda seção, descrevemos o percurso metodológico e procedimentos adotados. A terceira seção trata da contextualização do lócus da pesquisa, com uma breve apresentação dos fluxos escolares dos estudantes do ensino médio concomitante ao técnico na ETE FMC. Em seguida, apresentamos o referencial teórico a partir de três abordagens: os paradigmas educacionais, a qualidade na educação básica como direito a acesso, permanência e desenvolvimento dos estudantes; e o sucesso e insucesso escolar. Na seção cinco, apresentamos e discutimos os resultados. Por fim, expomos nossas considerações finais com discussão dos resultados dos fluxos escolares, achados das entrevistas e algumas preposições para continuação da pesquisa. 


\section{Percurso Metodológico}

O procedimento metodológico que empregamos nesta pesquisa foi 0 estudo de caso (STAKE, 1994 apud GODOY, 2006) que teve como campo empírico a Escola Técnica de Eletrônica Francisco Moreira da Costa (ETE FMC). Pela natureza da investigação, optamos pela abordagem qualitativa (STRAUSS, 2008) de delineamento exploratório (GIL, 2002).

A população da pesquisa se constitui de estudantes do ensino médio concomitante, do período de 2017 a 2019. Foram produzidos dados institucionais e realizadas oito entrevistas semiestruturadas, com estudantes reprovados e transferidos do $1^{\circ}$ ano do ensino médio concomitante em 2018, com foco nas suas experiências escolares considerando que estes apresentam maior índice de insucesso escolar em relação aos demais anos. As questões levantadas nas entrevistas despertam discussões sobre aspectos dos processos de ensino, de aprendizagem e de avaliação, qualidade do ensino na ETE FMC e, ainda, sobre o sucesso e insucesso escolar.

As entrevistas foram analisadas por meio da análise de conteúdo (BARDIN, 2016). Definimos as categorias de análise a partir do escopo do estudo e de suas relações com o referencial teórico. Assim organizamos como categorias: ensino, aprendizagem e avaliação, qualidade na/da educação e sucesso e insucesso escolar. Além disso, salientamos que, ao nos referimos aos entrevistados, usamos nomes de pedras preciosas brasileiras, para preservar sua identidade e anonimato. Dessa forma, para os estudantes reprovados, usamos os nomes Ágata, Alexandrita, Ametista e Diamante. Para os que estão entre os transferidos, Esmeralda, Topázio, Turmalina e Citrino.

\section{Contextualização do lócus da pesquisa}

A ETE FMC é uma instituição de educação básica privada, filantrópica e confessional integrante à Rede Jesuíta de Educação (RJE) e situada no município de Santa Rita do Sapucaí, em Minas Gerais (MG). Nela, são ofertados o ensino médio e educação profissional de nível técnico concomitante e subsequente.

A ETE FMC, quanto à gestão escolar tem as seguintes características: organização curricular com disciplinas comuns a todos os estudantes do curso técnico 
nos dois primeiros anos dos cursos diurno e no primeiro ano do curso noturno com escolha pela especificidade das ofertas no último ano, o que em alguma medida se aproxima da educação superior; aulas ministradas em salas e laboratórios temáticos em que os estudantes se deslocam para esses ambientes, conforme dinâmica curricular diária; e nos cursos diurnos, as aulas em mais de um turno. A estrutura física da instituição propicia diversidade nas práticas pedagógicas, as quais são ministradas por docentes com formação acadêmica qualificada e experiências profissionais relevantes. Dos 41 docentes em 2021, todos têm formação universitária, 17 docentes possuem especialização, 18 possuem ou estão cursando mestrado, e dois possuem ou estão cursando doutorado. Além de lecionar na escola, 11 professores lecionam em outra instituição de educação básica, seis em instituição superior e dois nas duas modalidades. Dos docentes da ETE FMC, 11 professores atuam na indústria além das aulas ministradas na escola.

A partir de dados institucionais de 2017, 2018 e 2019, foram analisados os fluxos escolares dos estudantes do ensino médio concomitante da ETE FMC, considerando aprovações, reprovações e transferências externas (quando os estudantes solicitam transferência para outra instituição, durante o ano letivo ou ao seu término). Esses dados foram observados, ainda, por meio de um recorte de beneficiários da Certificação das Entidades Beneficentes de Assistência Social ${ }^{3}$ (CEBAS).

Dos 451 estudantes matriculados em 2017, 263 foram beneficiários da bolsa CEBAS e 188 não foram. Em 2018, dos 405 estudantes matriculados, 254 foram beneficiários da bolsa CEBAS e 151, não. Por fim, em 2019, dos 426 estudantes matriculados, 260 foram beneficiários de bolsa CEBAS, enquanto 166 não foram.

Nos fluxos escolares dos estudantes, entre 2017 e 2019, a reprovação dos não beneficiários da bolsa CEBAS se manteve em torno de $5 \%$. Diferentemente desses, os bolsistas tiveram um aumento de $50 \%$ na reprovação e redução na taxa de transferência no mesmo período, como mostra o Quadro 1.

Comparando-se os dados, é possível inferir que há impacto direto sobre o número de reprovações quando os estudantes permanecem na escola, uma vez que o índice de aprovações se manteve constante ao longo dos três anos. Ou seja, os estudantes que costumam solicitar transferência ao longo do ano letivo,

\footnotetext{
${ }^{3}$ Bolsa concedida na proporção de cada nove estudantes pagantes matriculados através de análise do perfil socioeconômico com classificação da menor para a maior renda, conforme Lei 12.101/2009.
} 
especialmente os bolsistas, são os que têm maior possibilidade de reprovação, quando optam por permanecer o ano letivo completo na ETE FMC, segundo os fluxos apresentados.

Quadro 1 - Fluxo dos estudantes de 2017 a 2019 - bolsistas e não bolsistas

\begin{tabular}{|c|c|c|c|c|c|}
\hline \multicolumn{2}{|c|}{2017} & $\begin{array}{c}\text { Total de alunos } \\
\text { por grupo e série }\end{array}$ & Aprovados & Reprovados & Transferidos \\
\hline & $\begin{array}{c}\text { Não beneficiário } \\
\text { CEBAS }\end{array}$ & 188 & $79 \%$ & $5 \%$ & $15 \%$ \\
\cline { 2 - 5 } & $\begin{array}{c}\text { Beneficiário } \\
\text { CEBAS }\end{array}$ & 263 & $75 \%$ & $10 \%$ & $16 \%$ \\
\hline \multirow{2}{*}{$\mathbf{2 0 1 8}$} & $\begin{array}{c}\text { Não beneficiário } \\
\text { CEBAS }\end{array}$ & 151 & $88 \%$ & $5 \%$ & $7 \%$ \\
\cline { 2 - 6 } & $\begin{array}{c}\text { Beneficiário } \\
\text { CEBAS }\end{array}$ & 254 & $79 \%$ & $9 \%$ & $12 \%$ \\
\hline \multirow{2}{*}{$\mathbf{2 0 1 9}$} & $\begin{array}{c}\text { Não beneficiário } \\
\text { CEBAS }\end{array}$ & 166 & $88 \%$ & $4 \%$ & $8 \%$ \\
\cline { 2 - 6 } & $\begin{array}{c}\text { Beneficiário } \\
\text { CEBAS }\end{array}$ & 260 & $74 \%$ & $15 \%$ & $11 \%$ \\
\hline
\end{tabular}

Fonte: Elaborado pelas autoras, 2020.

É possível verificar que as taxas de insucesso escolar são mais acentuadas nos estudantes beneficiários da bolsa CEBAS, que se caracterizam como estudantes de classes menos favorecidas socialmente e oriundos de escolas públicas. Esse fator desperta debates sobre universalização e qualidade na educação, em especial no que concerne às instituições públicas que vêm sendo mais diretamente afetadas pela falta de investimentos, uma reflexão que não é recente e pode ser encontrada em autores como Dourado (2007), Padilha (2001), Gadotti (2013), entre outros.

A média de aprovados, reprovados e transferidos nos $1^{\circ}, 2^{\circ}$ e $3^{\circ}$ anos, entre 2017 e 2019, sustenta uma das inquietações que move esta pesquisa, indicando o aumento do insucesso escolar no $1^{\circ}$ ano do ensino médio concomitante, fator que conduziu a realização de entrevistas com reprovados e transferidos que compõem esse grupo.

Finalmente, sabe-se que fatores de ordem sociocultural (PADILHA \& SILVA, 2004) e socioambiental (PADILHA, 2001) podem estar associados ao insucesso escolar. Perrenoud (1999) atribui relevância a aspectos culturais relacionados às desigualdades quanto ao sucesso escolar - em outras palavras, as regras do jogo são diferentes em ambientes públicos e privados, mesmo em instituições do mesmo nível de ensino, o que pode ser fator de influxo na ETE FMC, uma vez que recebe estudantes de escolas com naturezas e localidades diversas. 


\section{Paradigmas educacionais, qualidade na educação e sucesso/insucesso escolar}

Esta pesquisa está fundamentada em conceitos acerca de práticas pedagógicas, discutindo determinados paradigmas educacionais; a qualidade na educação básica, expressa no direito ao acesso, à permanência e ao desenvolvimento dos estudantes; e, o sucesso e insucesso escolar.

Para nossa investigação, recorremos aos paradigmas pedagógicos da instrução, da aprendizagem e da comunicação sistematizados por Trindade e Cosme (2010) a partir conceito de triângulo pedagógico de Houssaye (1996, apud TRINDADE; COSME, 2010). É possível, ainda, compreender os paradigmas educacionais sob a perspectiva de Paulo Freire (2002; 2009), segundo suas reflexões sobre a "educação bancária" e a pedagogia libertadora que se caracteriza por sua natureza problematizadora e conscientizadora.

O paradigma da instrução, que se aproxima da educação bancária (FREIRE, 2005), nega o dialogismo na aprendizagem e tem a instrução como pilar da formação. Segundo essa visão, educar é ensinar, mas desconsiderando a perspectiva do estudante, num movimento verticalizado de transmissão de saberes. $O$ professor/disciplinador tem papel central e o estudante/disciplinado é mero receptáculo do conhecimento, permanecendo em escuta dócil. Aqui, a escola não funciona apenas "[...] como uma máquina de ensinar, mas também de vigiar, de hierarquizar, de recompensar (FOUCAULT, 2009b, p. 142)". Nessa dinâmica, os estudantes são passíveis e reprodutores de informações.

Por outro lado, o paradigma da aprendizagem é contrário ao da instrução. Nele, o estudante se desenvolve com autonomia, no processo de aprender a aprender, como indica Coll (1994). Nesse contexto, o estudante constrói seu próprio conhecimento, por meio de competências cognitivas e relacionais.

Fechando o triângulo pedagógico, temos o paradigma da comunicação, paradigma que de fato se opõe ao da instrução. Ele "[...] se caracteriza por valorizar a qualidade dos mais variados tipos de interacções que acontecem numa sala de aula como fator potenciador das aprendizagens dos alunos [...]" (TRINDADE; COSME, 2010, p. 58). Esse processo se daria a partir da apropriação do patrimônio cultural.

Quanto à qualidade na educação, devem ser considerados os atores envolvidos, a equidade, os aspectos socioeconômicos, processos e resultados. Além disso, é fundamental compreender o acesso e a permanência na escola como bens 
sociais e direitos de todos. Portanto, é indispensável a existência de projetos pedagógicos com diretrizes claras e refletidas nos processos de ensino/aprendizagem, avaliação processual e aprendizagem significativa. São igualmente essenciais as políticas públicas, os programas e projetos que busquem reduzir desigualdades e causem impactos positivos no desempenho dos estudantes, em ambientes intra e extraescolares. Esses aspectos são discutidos por organismos multilaterais, órgãos públicos como o Inep e autores como Bourdieu (1998) e Pacheco (2004).

Sob o prisma da educação jesuítica, a qualidade é compreendida a partir da formação integral, na qual os estudantes são levados "a participar e intervir autonomamente na sociedade", como resultado de "uma educação capaz de formar homens e mulheres conscientes, competentes, compassivos e comprometidos" (RJE, 2016, p. 37). Esse processo se daria em três dimensões da aprendizagem, a cognitiva, a socioemocional e a espiritual religiosa, dialogando com o paradigma da comunicação e a educação sociocultural (PADILHA \& SILVA, 2004) e socioambiental (PADILHA, 2001).

Para Padilha (2001), o fracasso escolar é fruto da incapacidade, carência, imaturidade, lentidão e retardo dos estudantes de camadas sociais mais empobrecidas. Para Arroyo (1992) e Perrenoud (1999), no entanto, o fracasso se relaciona não só com questões culturais, mas também com as desigualdades.

\section{Resultados e discussões}

Em análise inicial, foi possível perceber que, na ETE FMC, os efeitos dos processos de ensino, de aprendizagem e avaliação são mais latentes nos estudantes reprovados, visto que estes continuam na instituição. Por sua vez, os transferidos são marcados pela experiência de insucesso escolar. Nos tópicos seguintes, apresentamos e discutimos os resultados, a partir das categorias de análises, começando pelo grupo de estudantes reprovados e, na sequência, de transferidos.

\section{Categoria qualidade na/da educação}

Nesta categoria, o grupo de estudantes reprovados qualifica a ETE FMC como "diferente", em comparação com suas experiências escolares anteriores. Podemos relacionar essa percepção às práticas dos professores, à organização pedagógica e as condições de infraestrutura e recursos humanos da ETE FMC, cujo 
foco na formação integral das instituições jesuíticas se apoia em um Projeto Pedagógico de Rede - Projeto Educativo Comum. Desta forma, se evidenciam as assimetrias e desigualdades nas condições e ambientes entre escolas públicas e privadas no cenário brasileiro.

Gadotti (2013) se refere à democratização da educação como condição para que haja boa qualidade. Notamos que os entrevistados sustentam essa concepção: "Entrei na ETE e eu vi que aqui já era meio diferente". [...] "Aqui, os professores são diferentes, do jeito que te tratam aqui, eles vão te tratar em outra sala e na outra também" (Ágata).

Para Alexandrita, a rotina na ETE FMC é intensa e prepara melhor que as escolas anteriores. Em mais de um momento, a aluna comenta a forma de tratamento e de ensinar dos professores. Sobretudo o tratamento dado aos estudantes se relaciona ao postulado como qualidade na educação, por formar o sujeito em sua integralidade (RJE, 2016), esperado em colégios da Companhia de Jesus.

Segundo os entrevistados, outras duas dimensões que representam qualidade na educação estão relacionadas com a prática docente: o processo avaliativo e a organização/domínio de sala, por parte dos professores. Sobre a avaliação, os reprovados compreendem que ela é mais complexa e que exige mais dos estudantes. Consideram-se não apenas as notas, mas a verificação da aprendizagem, uma vez que no conselho final o estudante pode ser aprovado a partir de uma avaliação qualitativa, pelos professores da série. Tal aspecto dialoga com Dourado (2007), quanto aos recursos materiais e humanos, no currículo e/ou nas expectativas com relação à aprendizagem.

Pelo que revelam Ametista, Diamante e Alexandrita, a instituição promove avaliações somativas. Esse processo avaliativo nos remete à lógica instrucionista (TRINDADE; COSME, 2010), podendo promover desigualdade (GADOTTI, 2013) e, portanto, comprometer a qualidade. Sobre organização, dinâmica e controle de classe, Diamante expõe pontos positivos da ETE FMC: “Teve escola que eu já estudei que eu ficava conversando e o professor não chamava atenção e continuava por ali, e aqui o professor chama atenção" (Diamante). Apesar de Diamante entender como positiva a postura do professor da ETE FMC em repreender do estudante quando conversam, ela evidencia que as aulas são expositivas, mesmo que dialogadas, características de do paradigma da instrução. 
Entre os transferidos, pouco se falou sobre a categoria qualidade na educação. Nesse ponto, identificamos duas tendências. Uma delas é a compreensão de que a escola é injusta por reprovar; a outra trata da organização e do propósito educativo, tidos como distintos dos objetivos dos estudantes.

De acordo com Turmalina, a ETE FMC é injusta por sua rigidez e exigências, quando comparada às escolas onde estudou anteriormente. Além disso, relata que não desejava "perder tempo na ETE" (Turmalina) diante da possibilidade de reprovação, o que motivou sua transferência. Já Citrino não encontrou, na ETE FMC, um ambiente em sintonia com o momento que vivia, uma vez que a escola exigia dedicação e comprometimento: "Na ETE, é uma coisa mais séria, é muito mais completo" (Citrino).

As palavras "difícil" e "detalhezinho" são recorrentes entre os estudantes transferidos. O adjetivo "difícil" qualifica o ensino na escola, enquanto "detalhezinho" se refere a características do processo de ensino e aprendizagem que pode ser compreendido como positivo se relacionado à proposta pedagógica da instituição, no entanto como negativo do ponto de vista do entrevistado se considerado a exigência da instituição, mesmo que para essa seja seu propósito. Palavras como "mais", "muito", "tem", "bom", "prova" e "escola" também são ditas nas entrevistas intensifica os processos educativos da instituição em relação as demais, podendo ou não ser compreendido como positivo por parte do entrevistado, mas qualifica positivamente $o$ espaço investigado quanto a proposta formativa da instituição conforme seus documentos institucionais.

\section{Categoria ensino, aprendizagem e avaliação}

$\mathrm{Na}$ categoria ensino, aprendizagem e avaliação, a análise das entrevistas dos reprovados reitera aspectos de comparação da ETE FMC com as escolas anteriores desse grupo de estudantes. A maioria descreve a ETE FMC como diferente das outras escolas, valorizando as práticas pedagógicas nessa instituição, bem como a relação professor-aluno. A partir das respostas, percebemos que a relação interpessoal é horizontal. Os respondentes mencionam, também, a utilização de uma diversificação didático/metodológica em determinadas disciplinas, fatores que estão alinhados aos paradigmas da aprendizagem e da comunicação (TRINDADE; COSME, 2010). Sobre isso, Alexandrita afirma: "Eu nunca tive aquela sensação de aprender, quando eu não estudava aqui. Eu só vi a matéria lá e não entendi não aprende igual 
eu aprendo aqui" (Alexandrita).

Quanto às avaliações, esses estudantes destacam aspectos da aprendizagem, da contextualização e do propósito de verificação de seu desenvolvimento cognitivo, algo importante no paradigma da aprendizagem (TRINDADE; COSME, 2010). Nesse sentido, Diamante confirma: "A daqui tem mais a ver do que a de lá, porque a daqui tem mais detalhezinho, professor pergunta mais detalhezinho. Eu acho que é bom". Alexandrita compara os processos avaliativos do ensino fundamental, vivenciados anteriormente, aos da ETE FMC, classificando-os como diferentes. De todo modo, percebe-se que a estudante está se referindo a prova como estratégia de avaliação. Se a prova se constitui como única alternativa e/ou central, indica um alinhamento ao paradigma da instrução (TRINDADE; COSME, 2010).

Alexandrita demonstra satisfação ao conseguir aplicar conhecimentos adquiridos, algo que, no paradigma da comunicação (TRINDADE; COSME, 2010), é essencial para a consolidação do saber. Dessa forma, o processo avaliativo se conecta ao processo de ensino e aprendizagem, apresentado como satisfatório pela aluna. Diamante, do mesmo modo, valoriza a contextualização, aspecto que afetará os resultados das avaliações, por refletir aquilo que foi ensinado: "E tem professor também que dá bastante exemplo e eu acho que exemplo é essencial pra gente aprender algum conteúdo" (Diamante). Ressaltamos a importância de o professor buscar exemplos para facilitar a compreensão, todavia, evidenciamos um protagonismo do docente no processo e a estratégia da aula expositiva, o que se apresenta em congruência com o paradigma da instrução (TRINDADE; COSME, 2010).

Para os entrevistados reprovados, alguns professores desempenham papel importante e que Ihes serve de referência, destacando a posição que esses educadores ocupam na construção do conhecimento. A didática e metodologia, em algumas disciplinas, é validada pelo grupo como positiva e responsável pelo sucesso em sua aprendizagem. Alexandrita ilustra esse fato, dizendo que os docentes orientam seus esforços à aprendizagem de todos, sem distinções, independentemente do nível de cada um. $O$ aspecto da atitude e do compromisso dos docentes remete, novamente, ao paradigma da comunicação (TRINDADE; COSME, 2010). 
Alguns professores como "a professora de português ensina a gente de uma forma muito mais divertida, as aulas dela são muito mais confortáveis de você aprender. Então ela faz que a gente consiga aprender a matéria de uma maneira muito mais fácil" (Alexandrita). Esse relato evidencia o paradigma da aprendizagem (TRINDADE; COSME, 2010), no entanto, constata-se que não se trata da maioria, uma vez que a entrevistada pontua qual professora ela percebe a dinâmica pedagógica diferenciada.

Entrevistados percebem a busca de docentes por diversificar suas explicações, para que todos compreendam os conteúdos, o que se relaciona com o paradigma da instrução (TRINDADE; COSME, 2010), pois, mesmo que exista a busca pela diversificação, não há aqui uma evidência de mudança de paradigma para a obtenção da aprendizagem do estudante.

Indagados se os professores poderiam ter feito algo para evitar as reprovações, os estudantes novamente mencionaram elementos que reforçam a horizontalidade e acolhida docente, o que caracteriza paradigma da comunicação (TRINDADE; COSME, 2010). Mais de um entrevistado afirmou que os professores fizeram o possível, e que a responsabilidade pela reprovação está relacionada aos comportamentos inapropriados deles próprios ao longo do ano, já que foram advertidos quanto à dedicação e, no entanto, não se aplicaram. Esses aspectos são encontrados no paradigma instrucionista (TRINDADE; COSME, 2010), com os estudantes responsabilizando a si mesmos pela não aprendizagem - o que é um equívoco, já que a sociedade e instituição possuem responsabilidade pelo insucesso. Ainda assim, encontrarmos inúmeras questões históricas e culturais que reforçam esse tipo de pensamento.

Sobre a monitoria, programa ofertado pela ETE FMC, Alexandrita, ao comparar com as aulas regulares, demonstra como se dá a aprendizagem nas aulas, sendo essas instrucionistas (TRINDADE; COSME, 2010) e expositivas e os momentos da monitoria, que são descontraídos, com linguagem mais compreensiva e dinâmica, que se dá no paradigma da aprendizagem (TRINDADE; COSME, 2010).

"A monitoria é muito legal. Porque é uma forma de você aprender diferente do que só ficaria olhando para o quadro e escutando um professor falar [...] às vezes lá escutando amigo explicar a matéria de uma forma mais divertida é mais fácil de aprender" (Alexandrita). Segundo o relato, apesar de haver aulas tradicionais, a 
instituição promove momentos de aprendizagem seguindo outros paradigmas.

Ainda na mesma categoria, mas entre estudantes transferidos, a adjetivação da ETE FMC como "diferente" também apareceu, por meio de comparações com as escolas de onde se transferiram. Entre os pontos já apresentados, eles citaram a diferença em relação a conteúdos e disciplinas técnicas. Para Turmalina, a ETE FMC se diferencia das demais escolas por sua organização estrutural e pedagógica.

Os transferidos descrevem a atuação docente destacando elementos como atividades diversificadas e práticas, além do acompanhamento por parte dos professores - aspectos que se alinham aos paradigmas da aprendizagem e/ou da comunicação (TRINDADE; COSME, 2010). Contudo, o processo avaliativo contradiz essas práticas, pois se relaciona com o paradigma instrucionista, centrado na avaliação somativa (TRINDADE; COSME, 2010). Ainda assim, o acompanhamento docente foi avaliado positivamente.

A falta de afinidade com o curso técnico é, segundo alguns entrevistados, um fator que motiva o insucesso e/ou sua saída da instituição. Outro tópico que os transferidos revelam é sua dificuldade na aprendizagem. Para eles, as dificuldades ocorrem devido às lacunas ao longo de sua trajetória educacional, ainda que a ETE FMC seja mais exigente, como afirma Topázio. O mesmo estudante conta que o professor "me explicava" (Topázio), o que contradiz o paradigma da aprendizagem, por ser uma ação expositiva e pouco diversificada, em termos de práticas pedagógicas, relacionando-se ao paradigma da instrução. Embora a relação professor-aluno manifeste o paradigma da comunicação (TRINDADE; COSME, 2010), essa ação pode ter influenciado os resultados dos estudantes.

Sobre o papel dos professores no sentido de evitar sua transferência, esse grupo demonstra fortes indícios de culpabilização. Citrino diz que o "jeito que o professor explicava lá era muito bom, não teve nada a ver com os professores mesmo, com os professores não, foi mesmo coisa minha" (Citrino). No paradigma da instrução, a autorresponsabilização dos estudantes é uma concepção dominante. Portanto, não podemos excluir a influência da educação tradicional sobre o sujeito aprendente.

No grupo dos transferidos, há menções ao comportamento disciplinador de determinados docentes e à rigidez da escola. Nas palavras de Turmalina, "o professor ensinava quem tava realmente querendo aprender" (Turmalina). Isso evidencia a 
relação com o ensino, mesmo que não haja aprendizagem, o que é uma característica do paradigma da instrução (TRINDADE; COSME, 2010). Freire (2002) se refere a esse aspecto como "educação bancária", e Foucault (2009b), por "docilização dos corpos".

Em síntese, os estudantes quando comparam a ETC com suas escolas anteriores reconhecem e destacam aspectos positivos que envolvem especialmente os professores e as práticas pedagógicas, o que reforça no insucesso, a autorresponsabilização e a culpabilização dos estudantes. No entanto, identificamos sinais que indicam a coexistência de práticas docentes que transitam entre os paradigmas. As relações interpessoais horizontalizadas são características do paradigma da comunicação (TRINDADE; COSME, 2010). Percebeu-se também a diversificação didático metodológica por parte de alguns docentes, o que dialoga com o paradigma da aprendizagem (TRINDADE; COSME, 2010) mesmo havendo, ainda, uma predominância de aulas expositivas presentes no paradigma da instrução (TRINDADE; COSME, 2010).

\section{Categoria sucesso e insucesso}

Nesta categoria, a análise das entrevistas com estudantes reprovados demonstrou possíveis motivos relacionados ao insucesso escolar, como a dedicação e postura individual dos entrevistados. Ágata, por exemplo, conta que foi aconselhada a sanar dúvidas nas aulas e frequentar as monitorias ofertadas pela escola. No entanto, embora tenha seguido as recomendações, ela confessa que não o fez de maneira adequada.

A aluna também relata que só se deu conta do possível insucesso escolar ao final do ano letivo, no período de recuperação final, situação que se vincula ao paradigma da instrução (TRINDADE; COSME, 2010) na medida em que não se apresenta uma avaliação formativa, diagnóstica e processual. Ela menciona que "os professores e a ajuda estavam lá" (Ágata), que teve acesso aos docentes e apoio da escola, mas que ela própria não se envolveu ou permitiu ser auxiliada - percepções que remetem, mais uma vez, à lógica de funcionamento instrucionista. No mesmo contexto, observa-se que os estudantes buscam o ensino profissionalizante, não pela natureza ou propósito dessa modalidade, mas por expectativas de familiares, pela oportunidade de obterem qualificações profissionais ou pelo desejo de receberem educação de qualidade, possibilitada pela bolsa CEBAS. 
O alto nível de exigência da escola e dos professores em detrimento da baixa autopercepção dos estudantes sobre si mesmos e suas condições, combinado com a pressão da família e a não identificação com a escolha profissional, contribuem para o insucesso escolar. Alexandrita atribui seu insucesso à perda de foco: na realidade escolar, dedicava-se mais às relações interpessoais do que aos estudos. Entre outros fatores, o ingresso em cursos ou instituições com os quais os alunos não se identificam, como no caso de Alexandrita, relaciona-se, sob a ótica do insucesso escolar, com questões culturais (ARROYO, 1992; PERRENOUD, 1999), como a valor da escola, da aprendizagem e o papel da instituição na construção da cidadania.

Aprender a aprender foi um aspecto apresentado por Diamante, que relatou nunca ter tido essa experiência antes de ingressar na ETE FMC. Nenhum entrevistado havia mencionado essa questão, que caracteriza a realidade escolar de muitos estudantes, especialmente os da rede pública.

Sobre a possibilidade de os professores terem atuado para evitar a reprovação, esse grupo foi unânime quanto à autorresponsabilidade pelo seu insucesso. Isso mostra a predominância do paradigma da instrução (TRINDADE; COSME, 2010) nos processos educativos institucionais. Contudo, não se pode desconsiderar que os estudantes sofreram influência de questões sociais, econômicas e culturais (PERRENOUD, 1999; ARROYO, 1992), moldando sua compreensão sobre os processos educacionais, também a partir de uma ótica instrucionista (TRINDADE; COSME, 2010).

Tanto com os reprovados quanto com os transferidos, é recorrente a falta de afinidade com o curso técnico. Os motivos de ingressar na instituição, entre esses grupos, ora são relatados por influência familiar, ora pela reputação de que a ETE FMC oferece ensino de qualidade, para que possam melhores se qualificarem academicamente, com aprovações em vestibulares e ou instituições públicas ou, ainda, pela qualificação técnica na busca por melhores condições socioeconômicas no mercado de trabalho.

Além disso, a gestação durante a adolescência pode levar à transferência e culminar em evasão escolar, como ocorreu com Topázio. Em 2017, diante da reprovação iminente, a aluna abandonou a escola e retornou em 2018. Na metade do ano, com a gravidez e seus desdobramentos, a estudante solicitou transferência para outra instituição, onde ficou até o nascimento do bebê. Depois do parto, Topázio 
interrompeu os estudos e, até a data da entrevista, permanecia evadida.

Como motivações para sua transferência, Turmalina associa, na entrevista, elementos como a rigidez no processo de ensino e aprendizagem, a injustiça quanto à aprovação/retenção, a falta de afinidade com o curso e seu baixo desempenho escolar na ETE FMC. Dessa forma, notamos que sua compreensão se relaciona com questões sociais, econômicas e culturais (PERRENOUD, 1999; ARROYO, 1992).

Ainda tratando do grupo dos transferidos, quando questionada sobre o que os professores poderiam ter feito para evitar a saída, Esmeralda entende que os esforços dos docentes consistem mais em dar as aulas do que em interagir com os estudantes: "Acho que tinha que acolher mais, igual, tem muita discrepância de professor e aluno. Tipo, eles 'Ah, eu tenho que dar aula', entra, não preocupa tanto com o que cê tá sentindo" (Esmeralda). Esse tipo de interação remete ao paradigma instrucionista (TRINDADE; COSME, 2010).

Por outro lado, Citrino demonstra total satisfação com a escola e seus processos de ensino e aprendizagem, não associando sua transferência ao insucesso, mas ao distanciamento de seus objetivos pessoais. Contudo, sua atitude no âmbito educacional, de "apenas querer zoar" (Citrino), evidencia o fracasso escolar (SPOZATTI, 2000). Assim, sob o obscurantismo de questões socioculturais (ARROYO, 1992; PERRENOUD, 1999), o aluno não compreende a educação como emancipatória e libertadora (FREIRE, 2005).

\section{Considerações finais}

$\mathrm{Na}$ análise dos fluxos escolares, verificamos que a maior concentração de estudantes com insucesso escolar, reprovados e transferidos, está entre os bolsistas, beneficiários CEBAS. Também, observamos que o índice de insucesso se acentua no $1^{\circ}$ ano do ensino médio concomitante. Dessa maneira, concluímos que processos de ensino, de aprendizagem e de avaliação são fatores que influenciam os fluxos escolares, assim como a mudança de nível de ensino e de escola, visto que a ETE FMC não oferece os níveis anteriores.

Outro dado que afeta os fluxos as diferenças resultantes das experiências escolares anteriores e que se acumularam na ETC FMC, lacunas que se acentuam entre os estudantes de classes menos favorecidas que vêm da rede pública e recebem bolsa CEBAS, compondo o grupo com mais dificuldades acadêmicas. 
O insucesso dos estudantes também se vincula à falta de afinidade com o curso técnico, com um ingresso motivado pela influência de familiares e pela busca por educação de qualidade e/ou qualificação profissional. Associa-se o ingresso à busca de ascensão socioeconômica por meio da profissionalização, possibilitada pela concessão da bolsa CEBAS. Contraditoriamente, o insucesso revela aspectos perversos reproduzidos socialmente na lógica da meritocracia que é a responsabilização e culpabilização dos estudantes que se autopercebem incapazes e não merecedores.

Concluímos que os fluxos escolares são impactados pelos processos de ensino, de aprendizagem e de avaliação evidenciado por fatores positivos e negativos. Entre os fatores positivos, destacamos o aspecto atitudinal/comportamental dos professores, ao estabelecerem relações horizontais com os estudantes; a presença de aulas dinâmicas e diversificadas; e a qualificação docente, para melhor condução dos processos. É possível perceber que os membros da instituição procuram promover a aprendizagem e sinalizar as dificuldades para os estudantes de modo a contribuir para minimizar o insucesso escolar.

Quanto aos fatores negativos, destacamos questões como a fragilidade socioeconômica, elementos culturais, familiares e condições de aprendizagem dos estudantes advindos de classe menos favorecidas e da rede pública. Além disso, há de se considerar a predominância do paradigma da instrução entre docentes e estudantes, manifesto nas trajetórias educacionais ou em aulas/disciplinas desenvolvidas a partir desse paradigma.

Assim, acreditamos que não se trata de buscar culpados para os (des)arranjos nos fluxos escolares da instituição. No entanto, certos fatores influenciam positiva e negativamente a vida escolar dos estudantes. Nessa perspectiva, é preciso potencializar os efeitos positivos e minimizar os negativos, com formação docente de modo a que este possam refletir sobre suas práticas e as teorias que as fundamentam. É preciso considerar, por fim, os fatores intervenientes, que atuam sobre os fluxos escolares e desenvolver estratégias para o enfrentamento.

Uma possibilidade para sequência da pesquisa, na escola estudada, é o envolvimento de toda comunidade escolar, especialmente os professores, já que esses são atores importantes no processo de ensino e de aprendizagem e a considerar: a formação acadêmica e continuada, a experiência profissional, ou mesmo 
de vida, que agregam no trabalho desempenhado. Outra indicação é uma gestão que utilize mais os indicadores educacionais e demais fatores que podem influenciar no fluxo escolar dos estudantes da instituição com vistas a elaboração de propostas interventivas mais ágeis e eficazes.

\section{Referências bibliográficas}

ARROYO, M. G. Fracasso-sucesso: o peso da cultura escolar e do ordenamento da educação brasileira. Em Aberto, Brasília, v. 11, n. 53, p. 46-53, jan./mar. 1992.

BARDIN, Laurence. Análise de conteúdo / Laurence Bardin, tradução Luis Antero T.Reto, Augusto Pinheiro, São Paulo: Edições 70, 2016.

BOURDIEU, P. Escritos de educação. NOGUEIRA, M.A.; CATANI, A. (Org.). Petrópolis, RJ; Vozes, 1998 (Ciências sociais da educação).

BRASIL. Lei no 12.101 DE 27 DE NOVEMBRO DE 2009. Dispõe sobre a certificação das entidades beneficentes de assistência social. Diário Oficial da União, Brasília, Brasília. 27 nov. 2009 Disponível em: <http://www.planalto.gov.br/ccivil_03/_Ato2007-

2010/2009/Lei/L12101.htm\#: :text=Disp\%C3\%B5e\%20sobre\%20a\%20certifica\%C3 \%A7\%C3\%A30\%20das, 1996\%2C\%209.732\%2C\%20de\%2011\%20de>. Acesso em: 10 de fev. de 2020.

COLL, César. Piaget, o construtivismo e a educação escolar: onde está o fio condutor? In: TEBEROSKY, Ana; TOCHINSKY, Liliana. SUBSTRATUM. Tradução. Beatriz Affonso Neves. Porto Alegre: Artes Médicas, v. 1, n.1, p.145-164, 1997.

DOURADO, Luiz. A qualidade da educação: conceitos e definições / Luiz Fernando Dourado (Coordenador), João Ferreira de Oliveira, Catarina de Almeida Santos. - Brasília: Instituto Nacional de Estudos e Pesquisas Educacionais Anísio Teixeira, 2007. 65 p. (Série Documental) Disponível em: <http://portal.inep.gov.br/documents/186968/485287/A+qualidade+da+educa\%C3\% A7\%C3\%A3o+conceitos+e+defini\%C3\%A7\%C3\%B5es/8926ad76-ce32-4328-8a265139ccedddb4?version=1.3>. Acesso em: 10 de maio de 2019.

FARIA, Debora S. A. MOURA, Dante Henrique. Desistência e Permanência de estudantes de Ensino Médio do PROEJA. 2015 Disponível em: <https://doi.org/10.15628/holos.2015.3195>. Acesso em: 19 de mar. de 2019.

FERRAZ, Maria do Carmo Gomes. Exclusão na escola no contexto das políticas afirmativas: reprovação e evasão no Instituto Federal de Educação, Ciência e Tecnologia da Bahia - campus de Barreiras sob o olhar dos atores envolvidos no processo / Maria do Carmo Gomes Ferraz. - 2015. 215 f.: il. Disponível em: <http://repositorio.ufba.br/ri/handle/ri/18168>. Acesso em: 15 de mar. de 2019.

FOUCAULT, Michel. Vigiar e punir: nascimento da prisão. Rio de Janeiro: Vozes, 2009b. 
FREIRE, P. Educação como prática da liberdade. Rio de Janeiro. Paz e Terra; 2009

FREIRE, P. Pedagogia da autonomia. Rio de Janeiro: Paz e Terra, 2002.

FREIRE, P. Pedagogia do oprimido. Rio de Janeiro: Paz e Terra. 2005

Indicadores de fluxos escolares apontam queda na evasão para ensino fundamental e médio. Instituto Nacional de Estudos e Pesquisa Educacionais Anísio Teixeira - INEP, 2019. Disponível em: <http://portal.inep.gov.br/artigo//asset_publisher/B4AQV9zFY7Bv/content/indicadores-de-fluxo-escolar-apontamqueda-na-evasao-para-ensino-fundamental-e-medio/21206>. Acesso em: 20 de ago de 2020.

Índice de Desenvolvimento da Educação Básica (Ideb). Instituto Nacional de Estudos e Pesquisa Educacionais Anísio Teixeira - INEP, 2021. Disponível em: < https://www.gov.br/inep/pt-br/areas-de-atuacao/pesquisas-estatisticas-eindicadores/ideb>. Acesso em: 01 de jun de 2021.

Instituto Nacional de Estudos e Pesquisa Educacionais Anísio Teixeira - INEP. Censo escolar. Brasília, DF, 2018. Disponível em: <www.inep.gov.br>. Acesso em: 10 de fev. de 2020.

GADOTTI, Moacir. Qualidade na educação: uma nova abordagem. Anais do Fórum Estadual Extraordinário da Undime, São Paulo, SP, Brasil. 2013

GIL, Antonio Carlos. Como elaborar projetos de Pesquisa. São Paulo: Atlas, 2002.

GODOY, Arilda Schmidt. Estudo de caso qualitativo. In: SILVA, Anielson B., GODOI, C. K., MELLO, R. (Orgs.) Pesquisa qualitativa em estudos organizacionais: paradigma, estratégias e métodos. São Paulo: Saraiva, 2006.

MEIRA, Cristiane Araújo,1981 - A evasão escolar no ensino técnico profissionalizante: um estudo de caso no campus Cariacica do Instituto Federal do Espírito Santo / Cristiane Araujo Meira. - 2015. 118 f.: il. Disponível em: <http://repositorio.ufes.br/handle/10/1562>. Acesso em: 03 de mar. de 2019.

MORAIS, Cristiano Nívio de. Reflexões sobre o fluxo escolar no ensino médio: o caso da Escola Estadual Presidente Tancredo Neves. Dissertação (mestrado profissional) - Universidade Federal de Juiz de Fora, Faculdade de Educação/CAEd. Programa de Pós Graduação em Gestão e Avaliação da Educação Pública. P. 164. 2017. Disponível em <http://www.mestrado.caedufjf.net/reflexoes-sobre-o-fluxoescolar-no-ensino-medio-o-caso-da-escola-estadual-presidente-tancredo-neves>.

Acesso em: 24 de fev. de 2019.

PACHECO, Eliezer. Uma nova dimensão da aprendizagem. Brasília: Inep, 2004.

PADILHA, Anna Maria Lunardi (2001). Possibilidades de histórias ao contrário, ou, como desencaminhar o aluno da classe especial. $2^{\underline{a}}$ ed. São Paulo:Plexus Editora.

PADILHA, Paulo Roberto e SILVA, Roberto da, orgs,m 2004. Educação com qualidade social: a experiência dos CEUs de São Paulo: São Paulo, Cortez/ IPF. 
PERRENOUD, Philippe. Avaliação: da excelência à regulação das aprendizagens - entre duas lógicas. Porto Alegre; Artmed, 1999.

PONTILI, Rosangela Maria. Determinantes do abandono e atraso escolar de adolescentes no ensino médio: uma análise para a região Sul do Brasil / Rosangela Maria Pontili. - Toledo, PR: \{s.n\}, 2015. 191 f.: il. Disponível em: <http://tede.unioeste.br/handle/tede/2204>. Acesso em: 14 de mar. de 2019.

PONTILHO, Gabriela. Entenda as taxas de transição escolar e de rendimento dos alunos. Revista Nova Escola, 2012. Disponível em: <https://novaescola.org.br/conteudo/2849/entenda-as-taxas-de-transicao-escolar-ede-rendimento-dos-alunos>. Acesso em: 10 de fev. de 2020.

RJE, Rede Jesuíta de Educação. Projeto Educativo Comum - PEC. Rede Jesuíta de Educação. Rio de Janeiro: Ed. Edições Loyola, 2016.

SPOZATTI, Aldaíza. Exclusão Social e Fracasso Escolar. Em Aberto, Brasília, v. 17, n. 71, p. 21-32, jan. 2000.

STRAUSS, Anselm. Pesquisa qualitativa: técnicas e procedimentos para o desenvolvimento de teoria fundamentada / Anselm Strauss, Juliet Corbin;

Taxas de rendimento. QEdu Academia, 2021. Disponível em: <https://academia.qedu.org.br/censo-escolar/taxa-de-rendimento/>. Acesso em: 10 de jul. de 2021.

TRINDADE, Rui; COSME, Ariana. Escola, educação e aprendizagem: Desafios e respostas pedagógicas. Rio de Janeiro: WAK editora, 2010.

YOKOTA, Meire Satiko Fukusawa. Evasão no ensino técnico e técnico integrado ao ensino médio: um estudo de caso nos cursos técnicos em eletrônica, informática e mecatrônica da ETC Jorge Street do centro Paula Souza. Dissertação (mestrado profissional) - Universidade Federal de Juiz de Fora, Faculdade de Educação/CAEd. Programa de Pós-Graduação em Gestão e Avaliação da Educação Pública. P. 95. 2015. Disponível em: <http://www.mestrado.caedufjf.net/evasao-no-ensino-tecnico-e-tecnico-integrado-aoensino-medio-um-estudo-de-caso-nos-cursos-tecnicos-em-eletronica-informatica-emecatronica-da-etec-jorge-street-do-centro-paula-souza/>. Acesso em: 01 de mar. de 2019. 


\section{Caroline Lourenço de Almeida Ribeiro}

Santa Rita do Sapucaí, Minas Gerais, Brasil

Possui graduação em Licenciatura Plena em Filosofia pelo Centro Universitário do Sul de Minas (2009).

Pós-graduada em Formação de Docentes e Orientadores Acadêmicos em EaD (2011), em Inspeção Escolar (2012), em Psicopedagogia Clínica e Institucional (2013), em Filosofia (2014) e em Educação Jesuítica: Aprendizagem Integral, Sujeito e Contemporaneidade (2020). Mestra em Mestrado Profissional em Gestão Educacional pela Universidade do Vale do Rio do Sinos - UNISINOS (2020), atualmente é pesquisadora colaboradora da Universidade do Vale do Rio dos Sinos, no grupo de pesquisa Políticas Públiucas e Gestão Educacional Escolar, professora e coordenadora do Ensino Médio da Escola Técnica de Eletrônica Francisco Moreira da Costa (ETE FMC). Tem experiência na área de Filosofia, orientação e gestão educacional.

E-mail: carolinelar.2ls@gmail.com

Link do Lattes: http://lattes.cnpq.br/4645850459442044

\section{Rosangela Fritsch}

São Leopoldo, Rio Grande do Sul, Brasil

Graduação (1982) e Mestrado em Serviço Social (1995) pela Pontifícia Universidade Católica do Rio Grande do Sul, Doutorado em Educação (2006) pela Universidade do Vale do Rio dos Sinos (Unisinos) e Pós-doutorado pela Universidade do Porto. Atualmente é professora titular no Programa de PósGraduação em Educação (Acadêmico), na Graduação e Especializações da Unisinos. Pesquisadora e coordenadora do Grupo de Pesquisa Políticas Educacionais e Gestão Educacional e Escolar. Tem experiência em Gestão Universitária com atuação na coordenação de cursos de Graduação e Pósgraduação Lato Senso e áreas administrativas (Coordenadora do Setor Serviços Sociais e Benefícios e Gerência de Atenção ao Aluno). Tem experiência acadêmica e produção nas áreas de Educação, Administração e Serviço Social, atuando principalmente nos seguintes temas: Trabalho, Formação Profissional, Gestão de Pessoas, Trajetórias Profissionais, Políticas Educacionais, Políticas de Currículo, Gestão Educacional e Escolar, Avaliação Educacional e Indicadores de Qualidade. Participa como pesquisadora dos Grupos de Pesquisa: Currículo, Avaliação, Formação e Tecnologias educativas (CAFTe) da Universidade do Porto, Portugal, Rede Ibero-Americana de Estudos sobre Educação Profissional e Evasão Escolar (RIMEPES) - UFMG e História, Política e Gestão da Escola Básica UNISINOS, Grupo de Estudos e Pesquisas em Currículo, Ensino Médio e Juventudes Contemporâneas (GEPCEM/Unisinos), Trabalho Educação e Conhecimento - UFRGS. Atualmente é Diretora Acadêmica da Associação Brasileira de Prevenção da Evasão Escolar na Educação Básica, Profissional e Superior (ABAPEVE) e membro do Comitê Científico da Casa Leiria e da Revista Angolana de Ciências.

E-Mail: rosangelaf@unisinos.br

Link Do Lattes: http://lattes.cnpq.br/5203131170203547

\section{Recebimento: 27/08/2021}

Aprovação: 21/09/2021

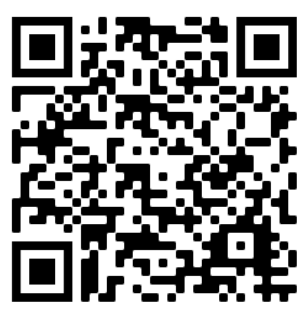

\section{Q.Code}

\section{Editores-Responsáveis}

Dr. Enéas de Araújo Arrais Neto, Universidade Federal do Ceará, UFC, Ceará, Brasil Dr. Sebastien Pesce, Universidade de Orléans, França 